
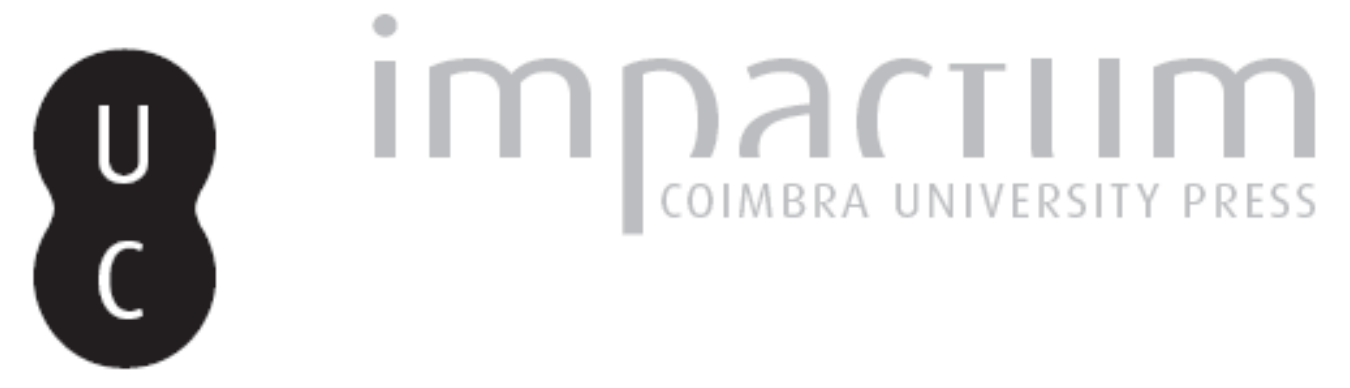

\title{
Los Vacceos en la Biblioteca Histórica de Diodoro de Sicilia
}

Autor(es): Salinas de Frías, Manuel

Publicado por: Faculdade de Letras da Universidade de Coimbra

URL persistente:

URI:http://hdl.handle.net/10316.2/37700

DOI:

DOI:http://dx.doi.org/10.14195/1647-8657_43_2

Accessed : $\quad$ 26-Apr-2023 02:16:03

A navegação consulta e descarregamento dos títulos inseridos nas Bibliotecas Digitais UC Digitalis, UC Pombalina e UC Impactum, pressupõem a aceitação plena e sem reservas dos Termos e Condições de Uso destas Bibliotecas Digitais, disponíveis em https://digitalis.uc.pt/pt-pt/termos.

Conforme exposto nos referidos Termos e Condições de Uso, o descarregamento de títulos de acesso restrito requer uma licença válida de autorização devendo o utilizador aceder ao(s) documento(s) a partir de um endereço de IP da instituição detentora da supramencionada licença.

Ao utilizador é apenas permitido o descarregamento para uso pessoal, pelo que o emprego do(s) título(s) descarregado(s) para outro fim, designadamente comercial, carece de autorização do respetivo autor ou editor da obra.

Na medida em que todas as obras da UC Digitalis se encontram protegidas pelo Código do Direito de Autor e Direitos Conexos e demais legislação aplicável, toda a cópia, parcial ou total, deste documento, nos casos em que é legalmente admitida, deverá conter ou fazer-se acompanhar por este aviso.

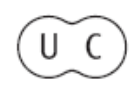


CONIMBRIGA

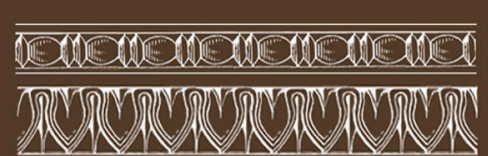

INSTITUTO DE ARQUEOLOGIA

VOLUME XLIII - 2004

FACULDADE DE LETRA

UNIVERSIDADE DE COIMBRA 
Manuel Salinas de Frías

Professor da Universidade de Salamanca

LOS VACCEOS EN LA BIBLIOTECA HISTÓRICA

DE DIODORO DE SICILIA

"Conimbriga" XLIII (2004) p. 47-62

RESUMEN: Análisis de los problemas relativos al pasaje de Diodoro de Sicilia sobre el colectivismo de los Vacceos $(\mathrm{V}, 34,3)$ a partir de la estructura y composición de los primeros libros de la Biblioteca Histórica. Palabras Clave: Vacceos, colectivismo agrario, Diodoro de Sicilia, etnografía antigua.

ABSTRACT: Analysis of the problems regarding the Diodorus of Sicily's passage on the colectivism of the Vacceans $(\mathrm{V}, 34,3)$ beginning from the structure and composition of his Bibliotheca Historica.

KEY WORDS: vacceans, agrarian colectivism, Diodorus of Sicily, ancient ethnography. 
(Página deixada propositadamente em branco) 


\section{LOS VACCEOS EN LA BIBLIOTECA HISTÓRICA DE DIODORO DE SICILIA}

El profesor Jorge de Alarcão acaba de publicar una renovadora obra sobre los pueblos del Noroeste y del Norte de la Península Ibérica llena de sugerencias. El concurso de los datos arqueológicos y antropológicos le permite plantear, en ella, nuevas y sugestivas hipótesis para estudiar la estructura social de los pueblos prerromanos de la Península. Queremos ofrecerle, como homenaje, esta pequeña contribución nuestra, sobre un tema que podríamos definir como "clásico", acerca de uno de los pueblos más importantes de la Meseta central, el de los vacceos y su supuesto régimen agrario colectivista, que ya estudiamos hace algunos años en un artículo publicado en la revista Veleia ${ }^{1}$. A lo dicho entonces, queremos añadir algunas precisiones.

\section{Las fuentes literarias y arqueológicas y su interpretación}

Una idea profundamente arraigada en la historiografía española es la de que, en la Antigüedad, la economía de los pueblos de la cuenca del Duero, y especialmente la de los Vacceos, se basaba en un régimen de propiedad colectiva de las tierras, dedicadas principalmente al cultivo cerealista. Esta idea se basa en un breve texto de Diodoro de Sicilia (Bib. Hist. V, 34, 3) que dice lo siguiente:

"El más dotado de los pueblos vecinos a éstos (los celtíberos, de los que acaba de hablar) es el conjunto de los que se llaman Vacceos. Éstos, en efecto, cada año distribuyen la tierra a los

1 Salinas de Frías, M. "Sobre las formas de propiedad comunal de la cuenca del Duero en época prerromana” Veleia 6, 1989, 103-110.

Conimbriga, 43 (2004) 47-62 
labradores, y poniendo en común los frutos, dan a cada uno una parte, y a los labradores que retienen algo les dan muerte como castigo". ${ }^{2}$

Entre los historiadores modernos, el primero en señalar la importancia del texto de Diodoro fue el abate Masdeu³, en el siglo XVIII; pero quien en realidad dio toda su importancia a este texto fue Joaquín Costa que, retomando la idea de Masdeu, señaló además la existencia de prácticas colectivistas en Sayago, Aliste y otras partes de Castilla todavía en la segunda mitad del siglo XIX. Para Costa, dichas prácticas eran la pervivencia del régimen conocido entre los Vacceos. Según Costa, "los Vacceos habían instaurado ya hace dos mil años el régimen colectivista propio del mir ruso de nuestros días, reproducido, si no tal vez perpetuado, en las mismas comarcas del Duero, en el concejo sayagués, en el campo de Aliste, etc., que hemos visto en pie todavía la víspera de la desamortización y que en gran parte ha seguido en funciones hasta el presente día"4. Según Costa, "los Vacceos poseían la tierra en común y distribuían los frutos obtenidos de ella entre las familias: únicamente para evitar los inconvenientes que habían debido experimentar en las labores ejecutadas en mancomún, individualizaban el trabajo"5. Él mismo, no obstante, advertía con respecto a las tierras arables destinadas al cultivo de cereales que estas tierras formarían una parte mínima del territorio de cada tribu ya que por Diodoro, por Estrabón y por Avieno sabemos que la economía predominante de estos pueblos era la economía pastoril y que por tanto la mayor parte de la tierra se dejaría para pastos que, con más razón que los cultivos, serían también de propiedad común ${ }^{6}$.

Con posterioridad a Costa, otros historiadores han explicado este rasgo de diferentes maneras. Para Ramos Loscertales, el colectivismo vacceo sería el resultado del régimen de vida de un pueblo en migra-

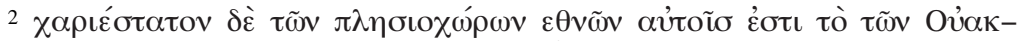

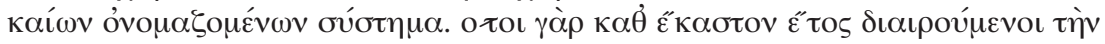

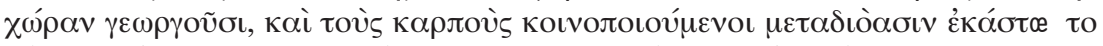

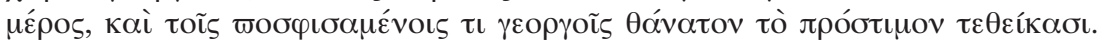

3 Juan Francisco Masdeu, Historia crítica de España y de la cultura española, III, Madrid 1875, 154.

4 Costa, J. Colectivismo agrario en España, Buenos Aires 1944, 311

5 Idem, p. 312.

6 Idem, p. 321. 
ción7. Para Viñas Mey, representaría la fusión de una cultura agrícola con otra pastoril ${ }^{8}$. Rostovtzeff comparó este sistema con el que podía observarse, según las fuentes antiguas, entre los dálmatas, los getas y los escitas ${ }^{9}$, opinión repetida por Caro Baroja y Blázquez Martínez, quienes subrayaron, sobre todo, el primitivismo de este sistema ${ }^{10}$. Para Ruipérez se trataría un régimen de tenencia de la tierra parecido al que se documenta en las tablillas micénicas ${ }^{11}$. M. Vigil señaló que las tierras a las que alude el texto de Diodoro debían ser territorios que eran propiedad colectiva de una comunidad gentilicia ${ }^{12}$. Fue este autor, precisamente, quien hizo mayores esfuerzos para poner en relación la noticia de Diodoro con otros textos o testimonios arqueológicos que permitieran comprender la naturaleza del colectivismo practicado por los Vacceos. Vigil utilizó a este respecto el texto de Frontino sobre el ager mensura per extremitatem comprehensus y el hallazgo por Taracena en Langa de Duero de un edificio de mayores dimensiones que el resto de las casas, dentro del cual halló un lote grande de herramientas agrícolas, lo que éste interpretó como un almacén comunal de herramientas de la comunidad que vivía allí13. Más recientemente, A. Domínguez Monedero ha vuelto sobre este texto defendiendo la historicidad del sistema descrito por Diodoro. Para este autor dicho sistema sería un sis-

7 Ramos Loscertales, J. M El primer ataque de Roma contra Celtiberia, Salamanca 1941, 16.

8 Viñas Mey, C. “Apuntes sobre historia social y económica de España” Arbor 158, 1959, 33 ss.

9 Rostovtzeff, M. Historia social y económica del Imperio Romano, Madrid 1972, 484 nota 58 refiriéndose al reparto de la tierra cada ocho años entre los dálmatas, que compara con el sistema de los Vacceos; y 492, nota 79, refiriéndose a la referencia de Horacio, carm. III, 24, a los getas y escitas, de la que deduce también un régimen comunal de propiedad, a pesar de la opinión de Kazarov, citada por él mismo, de que Horacio repetía un lugar común.

10 Blázquez Martínez, J.Ma "Economía de los pueblos prerromanos del área no ibérica hasta la época de Augusto" Estudios de economía antigua de la Península Ibérica, Barcelona 1968, 231; cf. también Caro Baroja, J. "Regímenes sociales y económicos de la España prerromana" Rev. Int. Soc. 1 (1943) 177.

11 Sánchez Ruipérez, M. «Notes on Mycenaean Land-Division and LivestockGrazing» Minos 5, 1957, 174 ss.

12 Vigil, M. Historia de España Alfaguara, vol. 1: Edad Antigua, Madrid 1973, 258-259.

13 Taracena, B. Excavaciones en las provincias de Soria y Logroño, MJSEA no $103,1929$. 
tema "autóctono", resultado del origen no indoeuropeo, o por lo menos no celta, de los Vacceos, que hundiría sus raíces en la cultura del Bronce Final $^{14}$ de la Meseta Norte que se caracterizaría, según el autor, por el predominio de una ganadería itinerante.

\section{Otras fuentes literarias y arqueológicas}

En relación con el texto de Diodoro se han puesto otras fuentes literarias y arqueológicas que, según algunos autores, vendrían a confirmar lo dicho por el autor griego. Son éstas un texto del agrimensor Julio Frontino acerca de un tipo determinado de campo y el hallazgo de un almacén comunal de herramientas en Langa de Duero.

\section{a. El texto de Frontino sobre el ager mensura comprehensus}

(De agrorum qualitate, p. 1): Ager est mensura comprehensus, cuius modus universus civitati es adsignatus, sicut in Lusitania Salmanticensibus aut in Hispania Citeriore Palantinis et in conpluribus provinciis tributarium solum per universitatem populis est definitum eadem ratione et privatorum agrorum mensurae aguntur hunc agrum multis locis mensores, quamvis extremum mensura comprehenderint, in formam in modum limitati condiderunt.

Ya a finales del siglo XIX, Max Weber había considerado que este tipo de campo sería característico de aquellas tierras que, separadas del ager publicus romano, no habían llegado a convertirse completamente en ager privatus ni estaban completamente libres de tributación ${ }^{15}$. Esta categoría agrimensoria, señala Max Weber, sería característica por ejemplo de las propiedades de los templos, pero también de las comunidades ciudadanas sujetas al pago de un stipendium, como dice el mismo Frontino: et in conpluribus provinciis tributarium solum. Los

14 Domínguez Monedero, A. "La campaña de Aníbal contra los Vacceos: sus objetivos y su relación con el inicio de la segunda guerra púnica” Latomus XLV, 1986, 241 ss.; especialmente, p. 248 y 252. Se basa este autor, para defender el carácter no indoeuropeo de los Vacceos, en la escasez de gentilitates en su territorio. Hallazgos recientes deberían modificar esta opinión. A nosotros el carácter indoeuropeo de este pueblo, por el contrario, nos parece bastante evidente.

15 Weber, M. Historia agraria romana, Madrid 1982, 36-37. 
dos ejemplos citados por Frontino, los Salmanticenses y los Palantini, son bien conocidos. Salmantica aparece mencionada por Ptol. II, 5, 9, que la cita como una ciudad de los vettones. Conocemos también dos términos augustales del año 6 de nuestra Era ${ }^{16}$ que marcaban los límites de los territorios de Mirobriga y Salmantica, por una parte, y de Bletisama, Mirobriga y Salmantica por otra. Igualmente dos inscripciones funerarias mencionan a individuos que se dicen salmanticenses, como referencia a la civitas de origo. En todos estos casos tanto el topónimo Salmantica como el adjetivo salmanticensis hacen referencia de forma evidente a una organización de tipo urbano y no a una comunidad gentilicia o tribal. Pallantia, por su parte, era una de las principales ciudades de los Vacceos y de toda la Meseta septentrional. A mediados del siglo I de nuestra Era Pomponio Mela (II, 88) la cita como una de las ciudades más florecientes del interior. Un poco después, Plinio (III, 26) la cita entre las principales civitates de los Vacceos, junto con Intercatia, Lacobriga y Cauca. Ptolomeo (II, 6, 50) la cita como una polis de los Vacceos.

Es decir, que por lo que respecta a las fuentes históricas, las comunidades citadas por Frontino eran comunidades urbanas, ciudades, y por consiguiente el tipo de campo descrito por este autor, el ager per extremitatem mensura comprehensus, no tiene nada que ver con el colectivismo agrario descrito por Diodoro, sino con el territorio de las ciudades que tenían la precisa condición jurídica de civitates stipendiariae $^{17}$. Recientemente E. Ariño ha publicado algunos documentos epigráficos que podríamos poner en relación también con este tipo de campos y con las mediciones efectuadas para delimitarlo ${ }^{18}$. Precisamente, lo atípico de estos monumentos ayuda a relacionarlos con los ambientes indígenas. Por otra parte, hay que tener en cuenta que los termini au-

16 CIL II, 857 y 859.

17 El ager per extremitatem, además, sería una forma creada por Augusto y difícilmente, por tanto, puede ponerse en relación con realidades prerromanas; cf. Hinrichs, F.T. Histoire des institutions gromatiques, Paris 1989, 121.

18 E. Ariño y M. García de Figuerola "Un terminus de agrimensor de carácter técnico procedente de la Sierra de Gata (Villamiel, Cáceres)" AEA 66, 1993, 258-265; cf. también E. Ariño y J. Rodríguez Hernández "El poblamiento romano y visigodo en el territorio de Salamanca. Datos de una prospección intensiva" Zephyrus 50, 1997, 225-245; M. Salinas de Frías "El poblamiento rural antiguo de la provincia de Salamanca: modelos e implicaciones históricas" Les campagnes de Lusitanie romaine (J.G. Gorges et M. Salinas eds.) Madrid-Salamanca 1994, 177-188.

Conimbriga, 43 (2004) 47-62 
gustales referentes al territorium de Salmantica se datan en época de Augusto y tienen relación, probablemente, con la reorganización provincial y la delimitación de las fronteras entre la nueva provincia Lusitania y la Hispania Citerior. No hay duda de que, desde comienzos del Imperio, Salmantica era una comunidad urbana.

Lo que podría ser la situación de la propiedad agraria en las ciudades indígenas durante la época republicana podríamos deducirlo extrapolando la situación que observamos en la ciudad celtibérica de Contrebia Belaisca. Un documento epigráfico del 15 de mayo del año 87 a. C. conserva la sentencia dada por el senado contrebiense en un litigio entre las civitates de los salluienses y los allavonenses por unos terrenos adquiridos por aquéllos a la civitas Sosinestana. El texto del documento contempla la posibilidad de que dichos campos fuesen ager publicus o ager privatus de los sosinestanos, de acuerdo con lo que parece normal de las ciudades antiguas de la Península Ibérica ${ }^{19}$; y aunque dichas ciudades estaban en el valle del Ebro no parecen existir razones para no suponer que la situación era la misma en las ciudades de la Meseta, ya que se organizaban de la misma manera como las fuentes literarias nos permiten ver.

\section{b. El hallazgo de Taracena en Langa de Duero}

En cuanto a los datos arqueológicos, no es necesario insistir en la dificultad de extraer conclusiones de tipo social y económico a partir de ellos. De ser cierta la identificación de Taracena del edificio mayor de Langa de Duero con un almacén comunal de herramientas, ello sólo significa que había útiles que eran de propiedad colectiva de la comunidad, lo cual puede implicar que había trabajos que se realizaban colectivamente, como rozas, por ejemplo, pero no necesariamente que las tierras fueran de propiedad colectiva ${ }^{20}$. Pero la existencia de útiles también en

19 Fatás, G. ContrebiaBbelaisca (Botorrita, Zaragoza) II: Tabula contrebiensis, Zaragoza 1980, p. 12: “...sei intra eos palos salluienses rivom per agrum publicum sosinestanorum iure suo facere liceret sei per agrum privatum sosinestanorum qua rivom fieri oporteret...”

20 A. Esparza señala la existencia también de una cerradura y una llave, que relaciona más bien con prácticas de propiedad privada (aunque la autoridad del poblado puede ser la custodia de los bienes depositados en el edificio, en nuestra opinión):

Conimbriga, 43 (2004) 47-62 
las casas implicaría, de acuerdo con este razonamiento, que había labores que se realizaban de forma privada y que existían tierras de propiedad privada. Frente a los escasos datos que pueden ponerse en relación con formas de propiedad colectiva, la mayor parte de los datos arqueológicos que conocemos sobre los Vacceos indican, por el contrario, la existencia de una sociedad desigual, con diferencias de riqueza más o menos acusadas, gobernada por una aristocracia militar que acumularía la mayor parte del excedente económico tanto en forma de ganados como de metales preciosos ${ }^{21}$. La existencia de tesoros celtibéricos, que se han interpretado como atesoramientos privados ${ }^{22}$, corroboraría dichas desigualdades sociales que son incompatibles con la imagen igualitaria que nos presenta Diodoro.

Por otra parte, frente a la existencia documentada en los poblados Vacceos de pequeños graneros, que hemos de suponer que guardaban las provisiones de cada familia, no tenemos atestiguado nada parecido que nos permita suponer la existencia de almacenes comunes desde los que se redistribuiría la cosecha. Las excavaciones de P. de Palol en el poblado vallisoletano de Soto de Medinilla, que se considera característico de la cultura vaccea, revelaron la existencia de pequeñas construcciones de adobe cuadradas o rectangulares con pisos de madera, atribuibles a la fase Soto II, dentro de las cuales se han hallado restos de cereal que parecen indicar que se usaban como graneros ${ }^{23}$. La pluralidad de estas construcciones y sus dimensiones relativamente pequeñas parecen sugerir que serían depósitos privados de grano. Estas estancias cuadradas han sido documentadas también, al lado de las casas circulares que

A. Esparza Arroyo, "Economía de la Meseta prerromana" Estudios de Economía Antigua en la Península Ibérica. Nuevas aportaciones, SHHA 17, 1999, 106, nota 40.

21 Sanz Mínguez, C. Cultura y ritos funerarios de un pueblo prerromano del valle medio del Duero. La necrópolis de Las Ruedas. Padilla de Duero (Valladolid), 1998, pp.498-504; el sector excavado corresponde, según el autor, a un área de enterramiento restringida a una capa social de estatus guerrero, así como a las personas, mujeres y niños, vinculados con ella.

22 Delibes, A., Esparza, A., Martín Valls, R. Y Sanz, C. “Tesoros celtibéricos de Padilla de Duero" en Arqueología Vaccea, 1993, 397-470, esp. 454-460; una crítica a las interpretaciones premonetales de estos tesoros en A. Esparza, art. cit., 110-112.

23 Wattemberg, F. La región vaccea, Madrid 1959, 176 ss.; Palol, P. De y Wattemberg, F. Carta arqueológica de España.Valladolid, Valladolid 1974, 188-193; Romero Carnicero, F. "La primera Edad del Hierro" en Historia deCastilla y León 1: La prehistoria del valle del Duero, Valladolid 1985, 89.

Conimbriga, 43 (2004) 47-62 
servían de habitación, en excavaciones realizadas en Montealegre de Campos y en Padilla de Duero, dos poblados Vacceos que alcanzaron la romanización ${ }^{24}$.

\section{EI texto de Diodoro en su contexto literario y cultural}

La falta de otros textos o de fuentes externas que corroboren lo dicho por Diodoro no deja otra alternativa que la del análisis directo del texto para su mejor comprensión. En este sentido, sin embargo, no parece que pueda avanzarse mucho sin tener el cuenta el contexto en que se sitúa la referencia al colectivismo de los Vacceos.

\section{a. Estructura de la obra (I, 4, 6-7)}

La Biblioteca Histórica de Diodoro de Sicilia consta de cuarenta libros de los cuales los 6 primeros se ocupan de los hechos anteriores a la Guerra de Troya y de relatos mitológicos; de ellos, los 3 primeros se dedican a la Historia Antigua de los bárbaros y los 3 siguientes a la de los griegos. Los libros VII-XXVII tratan el periodo que transcurre desde la guerra de Troya hasta la muerte de Alejandro Magno. Los libros XVIII-XL van, finalmente, desde las guerras entre los Diadocos hasta el comienzo de las guerras entre los romanos y los celtas, es decir, la conquista de las Galias por César en el año 59 a.C. El libro V queda incluido, por tanto, en la primera parte de la Biblioteca, es decir, la que trata los sucesos anteriores a la guerra de Troya y los mitos, en un contexto en el que las proyecciones utópicas de Diodoro hallan más fácil realización ${ }^{25}$. Dentro de la división que establece el propio Diodoro,

24 Heredero García, R. "Casas circulares y rectangulares de época vaccea en el yacimiento del Cerro del Castillo (Montealegre)" en Arqueología Vaccea, Valladolid 1993, 279-302; Gómez, A. y Sanz, C. "El poblado vacceo de Las Quintanas, Padilla de Duero (Valladolid): aproximación a su secuencia estratigráfica” ibid. 335-370, esp. 345-347. Un panorama general de la Meseta puede verse en A. Esparza Arroyo "Economía de la Meseta prerromana" en Estudios de Economía Antigua en la Península Ibérica. Nuevas aportaciones, SHHA 17, 1999, 87-123.

25 J. Campos Daroca, Introducción al libro I, Ed. Clásicas, Madrid, 109-113; cf. Sartori, F. "Nota sulla datazione dei primi libri della Bibliotheca Historica de diodoro Siculo" Athenaeum 61 (1983) y 62 (1984); Laqueur, R. "Diorea” Hermes 86, 1958,

Conimbriga, 43 (2004) 47-62 
corresponde a la parte que trata de los sucesos míticos y la historia antigua de los griegos, antes de la guerra de Troya.

En efecto, el contenido del libro $\mathrm{V}$ es el siguiente:

- Sobre los mitos que se cuentan sobre Sicilia y sobre la forma y tamaño de la isla.

- Sobre Deméter y Core.

- Sobre las Lípari y las islas Eolias.

- Sobre Melité, Gaulo y Cercina

- Sobre Aithaleia, Cirno y Cerdeña.

- Sobre las islas Baleares

- Sobre las islas del Océano que caen hacia el oeste

- Sobre Britania y las islas del ámbar

- Sobre Galia, Celtiberia, Iberia, Liguria y Tirrenia y sus habitantes y costumbres (caps. 24-40)

- Sobre las islas del Océano hacia el sur, las llamadas Hiera y Panchaia (caps. 41-46)

- Sobre Samotracia y sus misterios

- Sobre Naxos, Symé y Calidnes

- Sobre Rodas y sus mitos

- Sobre el Quersoneso frente a Rodas

- Sobre Creta y sus mitos

- Sobre Lesbos, Quíos, Samos y Cos

- Sobre Ténedos

- Sobre la colonización de Minos en las Cícladas.

En el cap. 24 Diodoro comienza describiendo las tierras que caen frente a las islas del Atlántico, que ha descrito anteriormente, y los pueblos que las habitan. Comienza describiendo la Céltica (Keltiké). El nombre de los celtas, galos o gálatas derivaría, según Diodoro, de $G a$ -

257-290; Stylionou, P. J. A historical commentary on Diodorus Siculus. Book 15, Oxford 1998; como muy bien advierte $\mathrm{M}^{\mathrm{a}}$ - Dolores Dopico en un fino y elegante artículo: "Ciertamente el mundo descrito por Diodoro es un mundo peculiar, en el que nos encontramos ante una mezcla de pueblos míticos de cuya existencia ya no se tenía noticia, como los Atlantes, con otros totalmente históricos como pueden ser los galos o los britanos" - "Un aspecto de la etnografía de Diodoro de Sicilia" en Scripta Antiqua in honorem Ángel Montenegro Duque et José María Blázquez Martínez, Valladolid 2002, 211-222; cita en p. 215. 
laté, hijo de Heracles y de una princesa celta a la que éste se unió cuando en el transcurso de su campaña contra Gerión pasó por la Galia y fundó Alesia. Describe su territorio, situado entre el Erídano (Ródano), el Reno (Rin) y el Ister (Danubio). Debido a la dureza del clima, los galos no cultivan ni la vid ni el olivo, pero son muy aficionados al vino, que les suministran comerciantes itálicos. Aunque no hay apenas plata en la Galia, dice, hay mucho oro. Describe la constitución física de los galos y su creencia en las doctrinas pitagóricas de la reencarnación de las almas. Cómo combaten, cómo visten; su aspecto terrorífico y su forma de hablar, exagerada y bravucona. La existencia entre ellos de "bardos" y "filósofos" a los que llaman "druidas". En el cap. 32 distingue que los que viven hacia el interior de Marsella, entre los Alpes y los Pirineos, son llamados celtas; mientras que los que viven más al norte, a lo largo del Océano y la selva Hercinia, son llamados galos; pero que los romanos llaman a todos comúnmente galos.

En el cap. 33 pasa a hablar de los celtíberos, que son vecinos (plesiojoroi) de los anteriores. Los celtíberos son el fruto de matrimonios mixtos de celtas e íberos. Describe su poder, su armamento y el método de fabricación de sus espadas. A pesar de ser aseados, dice, se lavan los dientes con orines. De costumbres son feroces, pero a los huéspedes los tratan como sagrados. Beben una especie de hidromiel y compran el vino a comerciantes.

De las tribus vecinas a los celtíberos, los más avanzados (jariéstatoi) son los Vacceos. Describe su forma de reparto de la tierra y, con un punto y seguido, continúa diciendo que los más valientes de los iberos son los lusitanos, a los que consagra el resto de la explicación, a su armamento y a su forma de combatir. A partir del cap. 35, hasta el 40, desarrolla una larga descripción de las minas de Iberia.

\section{b. ¿Es posible, pues, otorgar el valor de documento histórico a lo que cuenta Diodoro sobre el colectivismo de los Vacceos?}

Como acabamos de ver, la referencia al colectivismo agrario de este pueblo se inserta, como de pasada, en la transición entre la descripción de los celtas y la de los iberos, representada por los celtíberos que son una mezcla de ambos. La exposición que Diodoro hace de los celtas está plagada de tópicos que sirven para subrayar su barbarie frente, o por contraste, a la civilización de los griegos; también está 
llena de datos míticos como su descendencia de un Galatos, hijo de Heracles. En la descripción que hace, tanto de los celtas como de los iberos, insistiendo en conceptos como el de tryphé (lujo), se mezclan tópicos desfavorables junto con otros favorables, debidos a la concepción elaborada por la filosofía estoica del "buen salvaje" y del hombre no corrompido por la civilización ${ }^{26}$. Tener en cuenta estos prejuicios culturales podría ayudar a comprender el valor histórico de lo que dice Diodoro acerca del colectivismo agrario de los Vacceos.

Diodoro de Sicilia se adscribe a la ideología estoica, una de las escuelas filosóficas más importantes de la época helenística. En su complejo desarrollo, el estoicismo asumió dos aspectos muy diferentes e incluso contradictorios. Por una parte, al poner el acento en la pronoia o providentia divina, proporcionaba la base para una visión conformista del mundo sancionadora del orden establecido. Fue sin duda alguna por este aspecto por el que el estoicismo se convirtió en una de las ideologías o filosofías favoritas de la clase gobernante romana en la época de su expansión imperialista. Pero por otra parte, sirvió también para elaborar una serie de utopías igualitarias que sirvieron para fomentar, durante la época helenística, la contestación social o incluso la revuelta contra los romanos ${ }^{27}$. La base social de estas construcciones utópicas la proporcionaba el empobrecimiento creciente de un grupo cada vez mayor de la población griega.

Claude Mossé28 ha indicado la existencia de dos relatos utópicos, al menos, dentro de la Biblioteca Histórica de Diodoro, ambos en la primera parte, es decir, en la que se sitúa la referencia al régimen de propiedad de los Vacceos. Haciendo referencia a los movimientos de descontento social de la época helenística, Mossé recuerda la revuelta de Aristónico en Asia Menor, en el año 132 a. C., el cual daba a sus seguidores el nombre de heliopolitai (Str. XIV, 1, 38). Este nombre reaparece en un relato de Diodoro (II, 55 y ss.) que refiere el viaje de un tal Iambulos a las Islas del Sol, un país cuya característica esencial era la completa igualdad que había entre sus habitantes y la ausencia de esclavos

26 Lens et al. Introducción p. 111, valoran especialmente el papel de Dicearco; cf. Lens Tuero, J. "Sobre la naturaleza de la Biblioteca Historica de Diodoro de Sicilia" en Lens, J. (ed.) Estudios sobre Diodoro de Sicilia, Granada 1994.

27 T. A. Sinclair, A History of Greek Political Thoght, London 2 $2^{\mathrm{a}}$ ed. 1959, 256-259; Malcom Schofield, The stoic Idea of the City, Cambridge 1991.

28 C. Mossé, Histoire des doctrines politiques en Grèce, Paris 1969. 
en él. Mossé relaciona el nombre de los seguidores de Aristónico con el de los habitantes de las islas descritas por Diodoro, viendo en el atálida el adepto de un "igualitarismo utópico" que sería expresión de una corriente extendida en ciertos medios filosóficos o políticos de época helenística. El relato de Diodoro mezclaría elementos ya viejos, como el mito de la Edad de Oro, con la preocupación por el desequilibrio social, frente al cual estas utopías constituían una respuesta.

Otra utopía de esta clase es la que da el mismo Diodoro en el mismo libro en que se refiere a los Vacceos, poco después de hablar de ellos (V, 45). Se trata de la descripción de la isla de Panchaia por un tal Evémero, que se supone haber vivido hacia el 300 a. C. Esta isla ofrece la imagen de una sociedad organizada a la manera de las construcciones ideales utópicas características del pensamiento griego: los habitantes se dividen en tres clases, artesanos, agricultores y soldados y pastores. La propiedad privada no existe, cada uno sólo posee su casa y el jardín o huerto que la rodea. Los sacerdotes aseguran el reparto de los frutos de la tierra entre todos y se dan a sí mismos doble ración, lo que implica que ocupan un lugar aparte en la ciudad. Detalles concretos y realistas coexisten con nociones más abstractas. Como dice Mossé: "Il serait vain pourtant de chercher à localiser la Panchaia d'Euhemeros. Comme les îles du Soleil de Iamboulos, elle appartient au monde de l'utopie"29.

Me gustaría destacar también un hecho que me parece importante. A diferencia de la mayor parte de los historiadores modernos, que han interpretado el colectivismo de los Vacceos como un arcaísmo, para Diodoro Sículo dicho sistema se debía por el contrario a su mayor desarrollo. Los Vacceos son los vecinos más civilizados (jariéstatoi) de los celtíberos, dice expresamente. Esta afirmación sólo se comprende si se enmarca en una forma de pensamiento que veía en las sociedades utópicas de época helenística, como las que el mismo Diodoro describe en su propia obra, como la culminación deseable de la humanidad. La referencia de Diodoro al colectivismo de los Vacceos aparece pues cargada de connotaciones utópicas culturales y no es, como podría parecer a simple vista, la constatación desapasionada de un antropólogo objetivo. Con ello no quiero decir que sea una noticia inventada o falsa, pero sí que llama la atención que sea la única noticia que nos da sobre ellos. En este sentido, lo que no dice Diodoro es tan importante como lo que dice, para comprender este pasaje.

29 C. Mossé, op. cit. p. 106. 


\section{c. El problema de la veracidad histórica de la referencia sobre el co- lectivismo vacceo está relacionado, por otra parte, con otro: el de la fuente de Diodoro para esta parte de su obra.}

La descripción de las minas de Iberia que hace a partir del cap. 35 se debe, casi con toda seguridad, en su mayor parte a Poseidonio ${ }^{30}$. Algunos rasgos de la etnografía de las Galias también recuerdan a Poseidonio (por ejemplo los ríos y su papel estructurador del paisaje). Pero la distinción entre celtas y galos, tomando como referencia Marsella, y la referencia a los romanos, que los denominan por igual, creemos que puede remontarse a Polibio. Por otros textos, sabemos que Polibio se interesó por el armamento y la forma de combatir de la caballería celtibérica $^{31}$ y que habló de los Vacceos y celtíberos y de las ciudades que les pertenecían $^{32}$, lo mismo que hace Diodoro en el capítulo 34. Aunque hay referencias conjuntas a Polibio y a Poseidonio, por ejemplo, en el libro III de la Geografía de Estrabón al hablar de Celtiberia, parece que las refrencias de polibio eran más detalladas que las de Poseidonio. De Polibio, por otra parte, nos consta que estuvo en la Meseta, acompañando a Escipión Emiliano, mientras que de Diodoro no tenemos esa constancia. Por consiguiente, nosotros nos inclinaríamos a ver en esta referencia de Diodoro sobre los Vacceos un eco de Polibio.

Si ello es así, tanto más hay que lamentar que se hayan perdido los libros de Polibio sobre las guerras de los romanos en la Meseta, entre los que se debía hallar una descripción de las costumbres de sus habitantes. Es interesante constatar que de los abundantes datos polibianos, Diodoro no tome las referencias a la organización ciudadana o militar que sin duda debían existir en su fuente (conocemos la crítica de Estrabón a Polibio, acerca del número de ciudades en celtiberia: III, 4, 12; lo que quiere decir que había datos en este sentido en su obra), sino que presente a celtíberos y Vacceos como entidades indiferenciadas sobre

30 El problema de las fuentes de Diodoro ha sido uno de los más estudiados por la historiografía que, casi unánimemente, ha visto en él un mero recopilador: Sinclair, R. K. "Diodorus Siculus and the Writing of History" PACA 6, 1963; Cassola, F. "Diodoro e la storia romana" ANRW II.30.1, 724-773; Sacks, K. S. Diodorus Siculus and the first century, Princeton 1990; una defensa de su originalidad en Dopico Ma D. art. cit. 218-219; sobre el origen poseidoniano de la descripción de las minas hispanas, cf. C. H. Oldfather, Diod. Sicily, vol. III, London 1970, p. 196-197 nota.

31 Polibio, frg. 95.

32 Str. III, 4, 13. 
las cuales es fácil proyectar un rasgo o destacar otro, como el colectivismo, que de esta manera se convertía en algo paradigmático.

Para el lector de Diodoro de aquella época, la Iberia donde vivían los Vacceos no era más familiar que las islas del Océano frente a las cuales, según él, estaba situada. No aparece siquiera como una realidad geográfica, a diferencia de Sicilia, por ejemplo, en el mismo libro V, de la que da sus medidas y su forma. Su contemporáneo Varrón todavía desaconsejaba adquirir tierras en Lusitania debido al salvajismo de sus habitantes y al peligro de sus incursiones. El extremo occidental de la Oicúmene, recién conquistado, era pues un territorio lo suficientemente confuso como para que los bárbaros que lo habitaban pusieran ostentar las lacras de su condición salvaje, reflejada por ejemplo en el gusto por la ostentación del oro de los jefes galos, pero también algunos rasgos distintivos del buen salvaje, como la piedad y el respeto a los forasteros, a los que recibían como enviados por los dioses - justo lo que no se hacía en el turbulento mundo helenístico - o la ausencia de propiedad privada, como era el caso de los Vacceos. 